\title{
Fabrication, mechanical testing and application of high-pressure glass microreactor chips
}

\author{
Roald M. Tiggelaar ${ }^{\text {a,d, }}$, Fernando Benito-López $^{\text {b, } 1}$, Dorothee C. Hermes ${ }^{\text {a }}$, \\ Helmut Rathgen ${ }^{c}$, Richard J.M. Egberink ${ }^{b}$, Frieder G. Mugele ${ }^{c}$, \\ David N. Reinhoudt ${ }^{\mathrm{b}}$, Albert van den Berg ${ }^{\mathrm{a}}$, \\ Willem Verboom $^{\mathrm{b}}$, Han J.G.E. Gardeniers ${ }^{\mathrm{a}, \mathrm{d}, *}$ \\ ${ }^{a}$ BIOS, Lab-on-a-Chip Group, MESA+ Institute for Nanotechnology, University of Twente, P.O. Box 217, 7500 AE, Enschede, The Netherlands \\ ${ }^{\mathrm{b}}$ Supramolecular Chemistry and Technology Group, MESA ${ }^{+}$Institute for Nanotechnology, University of Twente, P.O. Box 217, \\ 7500 AE, Enschede, The Netherlands \\ ${ }^{\mathrm{c}}$ Physics of Complex Fluids Group, MESA+ Institute for Nanotechnology, University of Twente, P.O. Box 217, 7500 AE, Enschede, The Netherlands \\ ${ }^{\mathrm{d}}$ Mesoscale Chemical Systems Group, MESA ${ }^{+}$Institute for Nanotechnology, University of Twente, P.O. Box 217, 7500 AE, Enschede, The Netherlands
}

Received 12 December 2006; accepted 18 December 2006

\begin{abstract}
The design, fabrication and high-pressure performance of several in-plane fiber-based interface geometries to microreactor chips for highpressure chemistry are discussed, and an application is presented. The main investigated design parameters are the geometry of the inlet/outlet structure, the manner in which top and bottom wafer are bonded and the way the inlets/outlets turn over into the microfluidic channels.

Destructive pressure experiments with $\mathrm{H}_{2} \mathrm{O}$ and liquid $\mathrm{CO}_{2}$ showed that the maximum pressure that the proposed inlet/outlet structures can withstand is in the range of 180-690 bar. The optimal geometry for high-pressure microreactor chips is a tubular structure that is etched with hydrofluoric acid (HF) and suitable for fibers with a diameter of $110 \mu \mathrm{m}$. These inlets/outlets can withstand pressures up to 690 bar. On the other hand, small powderblasted inlets/outlets that are smoothened with HF and with a sharp transition towards the flow channels are adequate for working pressures up to 300 bar.

Microreactor chips with tubular inlet/outlet geometries were used for studying the formation of the carbamic acid of $N$-benzylmethylamine and $\mathrm{CO}_{2}$. These chips could be used for pressures up to 400 bar without problems/failure, thereby showing that these micromachined microreactor chips are attractive tools for performing high-pressure chemistry in a fast and safe way.
\end{abstract}

(C) 2007 Elsevier B.V. All rights reserved.

Keywords: High-pressure; Microreactor; Fabrication; Mechanical testing; Chemical application

\section{Introduction}

High-pressure conditions can enhance the rate and the equilibrium position of a variety of chemical reactions [1] as well as affect their conversion and selectivity [2]. Commonly used equipment for high-pressure chemistry are autoclaves combined with optical detection techniques [3] or NMR-probes [4]. High-pressure chemistry requires specialized, complicated and

\footnotetext{
* Corresponding author at: Mesoscale Chemical Systems Group, MESA ${ }^{+}$ Institute for Nanotechnology, University of Twente, P.O. Box 217, 7500 AE, Enschede, The Netherlands. Tel.: +31 53489 4356; fax: +31 534892575 .

E-mail address: j.g.e.gardeniers@utwente.nl (H.J.G.E. Gardeniers).

1 These authors contributed equally to this work.
}

expensive equipment due to the strict safety precautions. Miniaturisation of chemical processing units down to the micrometer scale offers a number of interesting advantages, including increased heat and mass transfer [5,6]. A feature of microreactors that is currently exploited is the presumption that "smaller is safer" [7], i.e. chemical processes at extreme pressure and temperature conditions and with toxic or explosive species can be studied without the safety issues associated with larger scale systems [8-10]. In this paper we focus on chemistry under high-pressure conditions, using a reaction system based on a microfluidic glass chip with a volume in the hundreds of nanoliter range. Future generations of such a microfluidic set-up may provide a convenient high-throughput experimentation platform for (automated) parallel synthesis and analysis of large numbers 
of "leads" for the development of specialty chemicals, and for the screening of parameter space for the relevant chemical routes to these chemicals.

In literature there is only limited information concerning microfluidic devices (i.e. microreactors) for high-pressure chemistry. In case of metal-plate based microreactors working pressures are up to 5 bar for gas-phase reactions [11], and up to 150 bar for two- and three-phase reactions [12,13]. For glassbased microreactors working pressures of $\sim 90$ bar are achieved [14]. In fact, the limiting factor to perform chemistry in microreactors at pressures above 150 bar is the quality of the connections to the microreactors [15]. Clamping of microstructured plates in a holder with metal tube connectors, in which sealing is achieved by compressed rubber O-rings, allows working pressures up to 150 bar [5]. When microfluidic chips made of silicon-glass or quartz are positioned in this type of clamp-holders or similar support units, reliable sealing pressures of $50-150$ bar can be obtained [16,17]. Alternative to this are connections of standard capillary tubing to microfluidic chips using (non-)epoxy based adhesives ( $\sim 2$ bar; permanent connection) [18,19], PDMS casting techniques ( 3 bar; permanent) [20], in situ melting and epoxy glueing (21 bar; permanent) [21] or PEEK interfaces with NanoPort ${ }^{\mathrm{TM}}$ assembly tools in combination with home-built chip holders (up to 100 bar, non-permanent) [22-24].

All these fiber-based interface methods are based on an out-of-plane connection of the fiber to the chip, in which the connections are made on the top surface of the chip, which lead to a rather fragile combination. By using an in-plane connection of the fiber to the chip a much more robust connection can be obtained, as will be demonstrated in this work for glass capillaries connected to a glass microreactor. The design, fabrication, and high-pressure performance of several in-plane geometries will be discussed, as well as an example of a chemical reaction performed in this chip.

\section{High-pressure glass microreactor layout, fabrication and interfacing}

In Fig. 1a, a picture of the microreactor is shown. The chip has two inlets (Fig. 1(1) and (2)) for introduction of pressurized fluids. After mixing in the first part of the microchannel, the fluid runs into a serpentine (Fig. 1(3)) in which chemical reactions can take place (length $13.5 \mathrm{~mm}$, width $\times$ height: $70 \mu \mathrm{m} \times 30 \mu \mathrm{m}$ ). This zone of the chip is heated. Subsequently, the fluid enters a flow restriction (Fig. 1(4)) with a length of $177 \mathrm{~mm}$ and a smaller cross-section $(20 \mu \mathrm{m} \times 5 \mu \mathrm{m})$, which ensures a virtually constant pressure in the reaction section (Fig. 1(3)) upstream and ends in a wider zone with outlets (Fig. 1(5) and (6)) in which the fluid mixture gradually expands to atmospheric conditions.

The microchannels in the chips were made by means of wet chemical etching in two separate $1.1 \mathrm{~mm}$ thick borosilicate glass wafers (Borofloat 33, Schott Technical Glasses, Germany) and direct bonding. For the first generation microreactors the in- and outlets were created by powderblasting, and the microchannels were realized with $25 \mathrm{vol} \%$ hydrofluoric acid (HF). The HF solution also smoothens the surface of powderblasted in- and outlets. After this, the in- and outlets were $600 \mu \mathrm{m}$ wide and $400 \mu \mathrm{m}$ deep. Upon stripping the chromium/gold mask layer and cleaning in $100 \%$ nitric acid $\left(\mathrm{HNO}_{3}\right)$ and DI water, a prebond was established and the wafer stack was annealed in air at $600{ }^{\circ} \mathrm{C}$ for $1 \mathrm{~h}$, followed by dicing of the individual chips. Capillary fused silica fibers (Polymicro Technologies, USA) were connected to the chips using two-component glue.

In the first generation high-pressure microreactors the silica fibers had an outer diameter of $360 \mu \mathrm{m}$, with inner diameters of 40 and $10 \mu \mathrm{m}$ for the inlet and outlet fibers, respectively, and epoxy glue was used (Araldite Rapid ${ }^{\mathrm{TM}}$, Ciba-Geigy, Switzerland) [25]. During preliminary experiments in continuous flow mode it turned out that chip-failure at pressures above 80 bar mostly occurred at one of the inlets. Therefore, different inlet/outlet configurations and bonding procedures were implemented in dedicated test-chips (Fig. 1b) to investigate which design results in the highest working pressures. Two main design parameters were studied: (i) the geometry of the in-plane inlet/outlet structure combined with the manner in which top and bottom wafers are connected (Fig. 2) and (ii) the manner in which the in/outlets connect to the microchannels (Fig. 3).

Fig. 2a shows the cross-sectional sideview of the basic inplane inlet/outlet geometry. The maximum pressure $\left(p_{\max }\right)$ this geometry can withstand can be improved by avoiding sharp corners where stress-concentrations occur [25]. The latter can be reduced by implementing small cappings in the top wafer (Fig. 2b). Alternatively, the use of smaller fibers, and thus smaller inlet/outlet holes, reduces the load on bond edges, resulting in

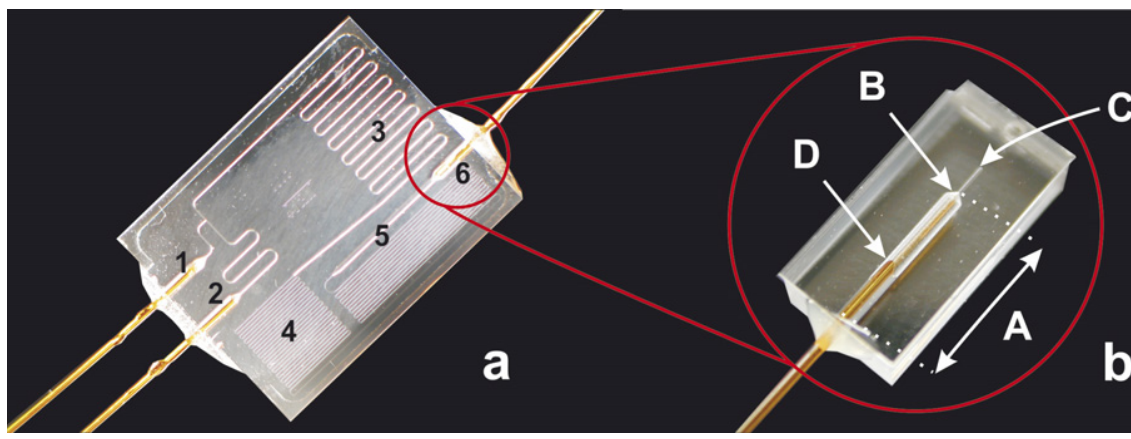

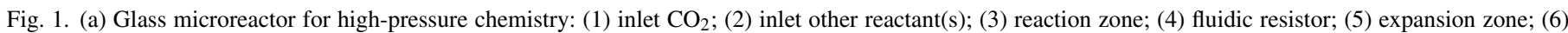

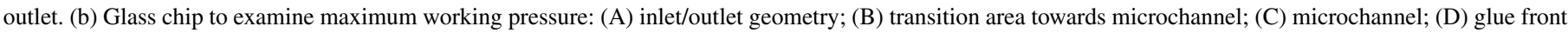
(meniscus). 
(a)

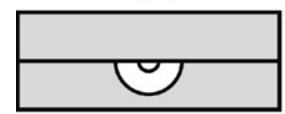

(d)
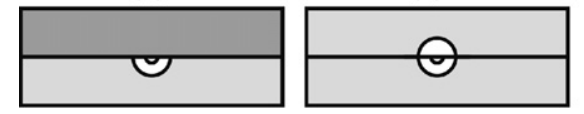

Borofloat Silicon

Fig. 2. Cross-sectional views of five different in-plane inlet/outlet geometries.
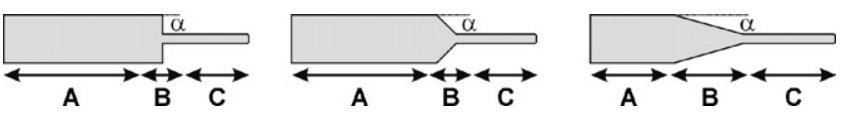

Fig. 3. Top views of three transitions from inlet/outlet to microchannel: flat tip (left, $\alpha=90^{\circ}$ ), tapered tip (middle, $\alpha=45^{\circ}$ ) and sharp tip (right, $\alpha=15^{\circ}$ ). (A) Inlet/outlet geometry; (B) transition area towards microchannel; (C) microchannel.

higher $p_{\max }$-values (Fig. $2 \mathrm{c}$ and d). The shape that should withstand the highest pressure is a perfectly circular one, Fig. $2 \mathrm{e}$ [26]; however, in practice this situation is extremely difficult to achieve [25]. In Fig. 2e, a circular cross-section is shown, which is theoretically the shape that can withstand the highest pressures. The inlet/outlet geometries shown in Fig. $2 \mathrm{a}-\mathrm{c}$ and e are based on direct bonding of two glass wafers. Since it is well known that this bond is less strong than an anodic bond (glass-silicon), also a geometry based on anodic bonding is tested (Fig. 2d).

The fabrication of geometry (Fig. 2a) is described above. The capping that covers the powderblasted and HF-smoothened geometry (Fig. 2b) is made with $\mathrm{HF}$ (depth $5 \mu \mathrm{m}$, width $430 \mu \mathrm{m}$ ). Geometries (Fig. 2c-e) are designed to be used in combination with smaller fibers (outer diameter $110 \mu \mathrm{m}$ instead of $360 \mu \mathrm{m}$ ). The fabrication of geometries (Fig. 2c and d) is identical to the procedure for geometry (Fig. 2b), but the powderblasted (and HF-smoothened) in/outlet is smaller: geometry (Fig. 2c) $180 \mu \mathrm{m}$ wide and $135 \mu \mathrm{m}$ deep after powderblasting, whereas these values were 580 and $390 \mu \mathrm{m}$ for geometry (Fig. 2b), respectively. Following on powderblasting the depth of the in/outlet is increased to $400 \mu \mathrm{m}$ (geometries, Fig. 2a and b) or $145 \mu \mathrm{m}$ (geometries, Fig. 2c and d) by HF-etching
( 25 vol.\%). The capping covering geometry (Fig. 2c) is $5 \mu \mathrm{m}$ deep and $210 \mu \mathrm{m}$ wide (fabricated using HF). Geometry (Fig. 2e) is realized with HF-etching only. In this case, in both wafers a half-circular structure was revealed (isotropic etch profile: width $120 \mu \mathrm{m}$, depth $55 \mu \mathrm{m}$ ) that after alignment and bonding results in a tubular inlet/outlet structure.

As can be seen in Fig. 1b, the inlet/outlet geometry turns over in a microchannel. Three different transitions towards this channel, that is etched with $\mathrm{HF}$ ( $70 \mu \mathrm{m}$ wide, $30 \mu \mathrm{m}$ deep and $2 \mathrm{~mm}$ long), are implemented in the geometries that were made with powderblasting and HF-etching (Fig. 2a and d). Top views of these different transitions are shown in Fig. 3. Due to the fact that geometry (Fig. 2e) is fabricated with isotropic etching only, for this inlet/outlet structure only a (near) flat transition is realized.

For direct bonding of the borofloat wafers two procedures are used. The first (standard) procedure (i) is as follows: after processing the substrates are cleaned in $\mathrm{HNO}_{3}(10 \mathrm{~min})$ and DI water, immersed in $\mathrm{KOH}\left(75^{\circ} \mathrm{C}, 25 \mathrm{wt} . \%\right.$, 1 min), rinsed in DI water (10 $\mathrm{min})$ and spin dried. After alignment and pre-bonding, the wafer sandwich is annealed at $600^{\circ} \mathrm{C}(1 \mathrm{~h}$, ramp up $6 \mathrm{~h}$, ramp down $12 \mathrm{~h}$ ). The second (upgraded) procedure (ii) is the same as (i), but with an additional cleaning step to remove organic contaminants, which consists of immersion in $\mathrm{HNO}_{3}$ (5 min) and DI water rinsing, followed by dry spinning. In addition to this, in the second procedure after alignment and pre-bonding the waferstack is compressed with a force of 11 metric tons (approximately 137 bar) for $30 \mathrm{~min}$ using an hydraulic flat-plate system. During this compression the temperature is $\sim 343^{\circ} \mathrm{C}$. Finally, the wafer stack is annealed at $600^{\circ} \mathrm{C}(1 \mathrm{~h}$, ramp up $6 \mathrm{~h}$, ramp down $12 \mathrm{~h}$ ). Procedure (ii) is implemented to further reduce the influence of contaminants (probably organic residues [27]) that are responsible for the appearance of voids/bubbles/blisters on the interface during annealing [28].

The silicon-glass stack is bonded anodically at $400{ }^{\circ} \mathrm{C}$ under a nitrogen atmosphere (bonding potential $400 \mathrm{~V}$ for $20 \mathrm{~min}$ ).

After dicing, fibers were glued in the different in-plane inlet/outlet geometry test-chips. Two types of epoxy resin, Araldite Rapid ${ }^{\mathrm{TM}}$ (Ciba-Geigy, Switzerland) and Loctite ${ }^{\circledR}$ (Henkel Adhesives, Germany), were used to glue the fibers (outer diameters 360 and $110 \mu \mathrm{m}$, respectively). Both glues are

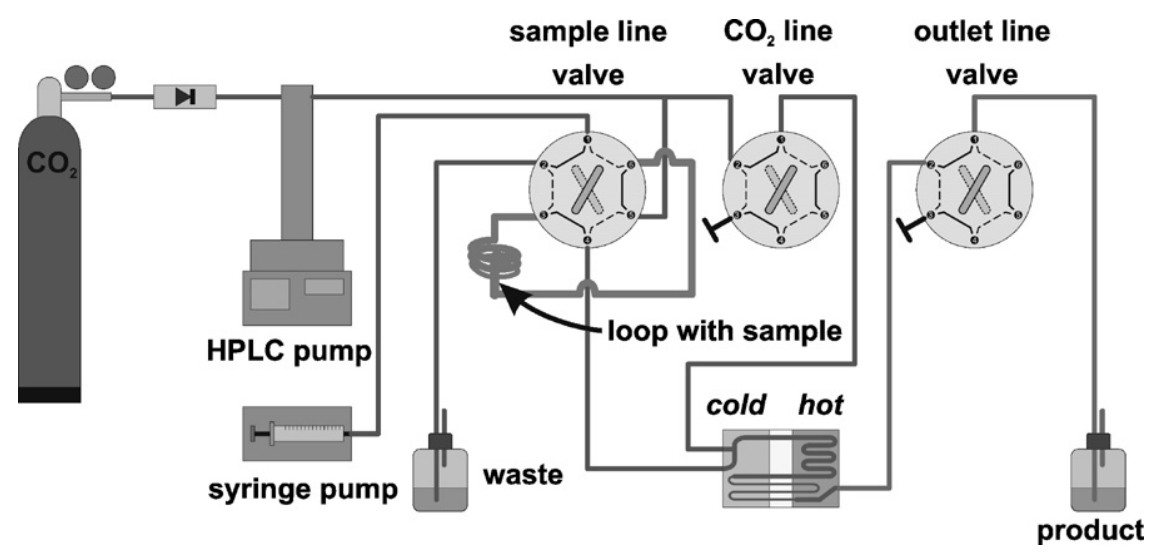

Fig. 4. Schematic view of the set-up used for reactions in high-pressure glass chips. 
resistant to commonly used solvents and have a relatively high viscosity, which is necessary to avoid capillary filling of the fibers and/or microchannels with the resin. Glueing was done at least $8 \mathrm{~h}$ before pressure testing (Fig. 4).

\section{Experimental}

\subsection{Bond inspection}

Prior to dicing the bond interfaces were inspected at waferscale to verify the presence of voids, blisters or bubbles on the interface: these bond-errors can easily be seen with a microscope or by eye. Subsequently, with confocal microscopy the quality of the bond was investigated directly at the interface. A home-built sample scanning confocal microscope was used that is adapted for the quantitative measurement of reflection coefficients down to $10^{-6}$. The measurements are based on the so-called $z$-scan of a confocal microscope. During the movement of a flat interface with reflectivity $R$ through the focus of a beam (i.e. along the optical $z$-axis; see inset Fig. 5), the detector intensity $I$ is recorded. The intensity can be expressed as (Eq. (1)) [29]:

$I(u) \sim R\left(\frac{\sin (u)}{u}\right)^{2}$

where $u$ is a normalized coordinate on the optical axis ( $u$ is related to the real axial $z$-coordinate via $u=z \pi \mathrm{NA}^{2} / \lambda$, with NA the numerical aperture of the objective lens and $\lambda$ the wavelength of the light). Usually the quantity of interest is the full-width at half-maximum (FWHM) of this center peak, which determines the capability of distinguishing two objects (point like) that are located behind each other on the optical axis, and this determines the superior depth discrimination of the confocal microscope.

When a bonded waferstack is illuminated with visible light about $4 \%$ of the incident light is reflected from the surface of the stack, whereas only less than $10^{-4} \%$ of the incident light is reflected from the bonding interface (this interface is assumed to

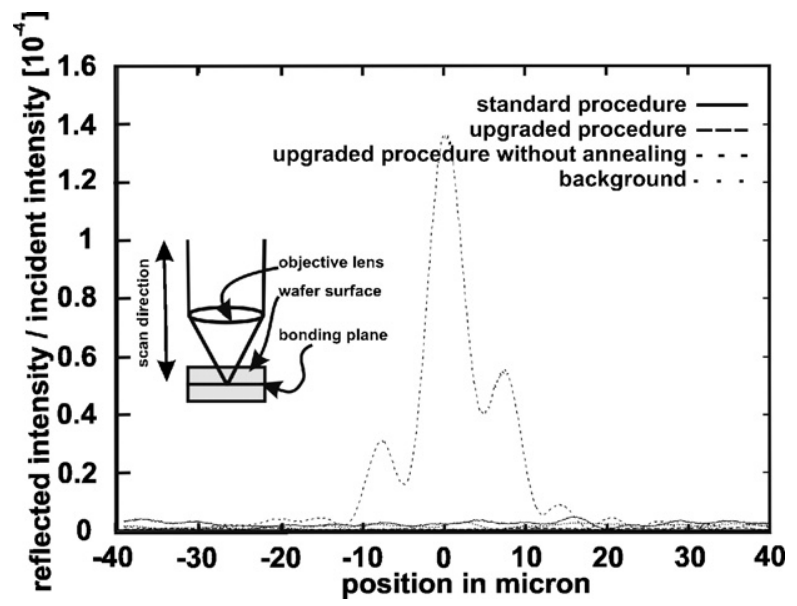

Fig. 5. Measured reflection at bond interfaces after performing the standard bond procedure (solid line), the upgraded bonding recipe (dashed line) and after the upgraded procedure excluding annealing at $600^{\circ} \mathrm{C}$ (broken line). The background signal corresponding to the residual reflection from the surface of the stack is represented by the dotted line. be a single dielectric layer with a thickness much smaller than the wavelength. For such thin layers, the reflectivity scales quadratically with its thickness). As a consequence, optical inspection of the interface is only possible if a method is available to discriminate between the (small) reflection from the bonding plane and the (large) reflection from the surface of the stack. This can be accomplished by using a feature of Eq. (1), namely that $I(u)$ decreases with $z^{2}$ for large $z$-values (the intensity $I$ of defocused objects decreases quadratically with $z$ ).

The wafers used in this work have a thickness of $1.1 \mathrm{~mm}$. Thus, if the bond interface is in focus, the surface of the stack is $1.1 \mathrm{~mm}$ out-of-focus. This leads to a suppression of the reflection from the surface by a factor of approx. $10^{-6}$, as can be calculated with Eq. (1) (NA used in the setup is $0.33 ; \lambda$ of the light source is $488 \mathrm{~nm}$ ). The corresponding residual intensity signal (background) determines the resolution of the setup and is plotted in Fig. 5 (dotted line).

At the bond interface the $z$-value is defined as zero. From Eq. (1) it follows that for $z=0 I(u)$ equals $R$, which means that the magnitude of the center peak of the $z$-scan directly yields the reflectivity. The reflectivity $R$ of the bond interface is related to its optical thickness $n d$ (Eq. (2)) [30]:

$R=\left(\frac{4 \pi}{\lambda} n d\right)^{2} \frac{\left(n-n_{0}\right)^{2}}{\left(n+n_{0}\right)^{2}}$

with $n$ is the refractive index of the interface material, $d$ the thickness of the interface and $n_{0}$ is the refractive index of the surrounding medium (borofloat glass).

Thus, when bonded glass-glass interfaces show a reflectivity (significantly) larger than the background signal, the thickness of the interface can be estimated. In other words, this method can be used to verify the quality of direct bonds. The method will be described in detail elsewhere [31].

\subsection{Pressure tests}

The maximum pressure $\left(p_{\max }\right)$ that the proposed in-plane inlet/outlet geometries (Figs. 2 and 3) can withstand was tested with $\mathrm{H}_{2} \mathrm{O}$ and $\mathrm{CO}_{2}$. The fused-silica capillaries were used to connect the chips to a high-pressure syringe pump (model 100DM; Teledyne Isco Inc., Lincoln, USA) using stainless steel fittings (F-140 \& A-318, Upchurch Scientific, USA). The chips were cooled to $10{ }^{\circ} \mathrm{C}$ via a home-built Peltier element (CP 0.8-7-06L, Melcor, USA). After filling the chip with liquid $\mathrm{CO}_{2}$ (starting pressure 65 bar) or $\mathrm{H}_{2} \mathrm{O}$, the pressure in the chip was increased using a constant flow rate $(2000 \mu \mathrm{l} / \mathrm{min})$. During these destructive experiments the pressure was logged with a PC. A sudden pressure drop indicated chip failure. Failure is accompanied by the formation of a small $\mathrm{H}_{2} \mathrm{O}$-droplet or ice formation due to $\mathrm{CO}_{2}$ expansion: no explosions occur when a microreactor chip of such a small size fails.

\subsection{Reaction in high-pressure glass microreactor chip}

Glass microreactor chips as described above were used to study the formation of benzylmethylcarbamic acid $(\gamma)$ by reac- 


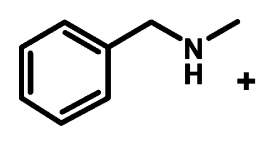

(1)

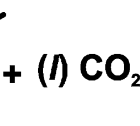

(2)

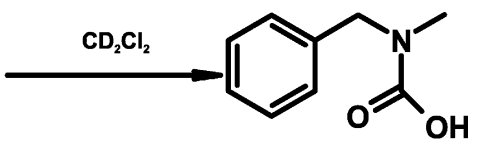

(3)
Scheme 1. Carbamic acid formation by reaction of $N$-benzyl methylamine $(\alpha)$ and $\mathrm{CO}_{2}(\beta)$.

tion of $N$-benzyl methylamine $(\alpha)$ and $\mathrm{CO}_{2}(\beta)$ (Scheme 1) at different pressures and temperatures.

Reactions of $\mathrm{CO}_{2}$ with amines are important for industrial processes, for example in the synthesis of alkylcarbamates and alkylisocyanates $[32,33]$ as well as for removal of $\mathrm{CO}_{2}$ from gas streams [34]. It is known that $\gamma$ is formed at supercritical $\mathrm{CO}_{2}$ conditions [35]. In Fig. 4 a schematic diagram of the set-up is shown.

Liquid $\mathrm{CO}_{2}$ (purity $\geq 99.7 \%$ ) was supplied from a cylinder and further pressurized with the high-pressure pump. The $\mathrm{CO}_{2}$ flow was split into two streams (50-50\%), to both directly feed the chip via the $\mathrm{CO}_{2}$ inlet and to drive the other reactant (anhydrous solution of $N$-benzylmethylamine in $\mathrm{CD}_{2} \mathrm{Cl}_{2}, 0.05 \mathrm{M}$ ) from a looping into the microreactor. A set of valves (Rheodyne C6W, Valco Instruments Co. Inc., USA) was used to control the flows to/from the chip (injection of liquid $\mathrm{CO}_{2}$, injection of sample via the looping, as well as closing/opening of the inlets and outlet), whereas in-line filters (type A-102, Upchurch Scientific, USA) prevented the channels in the chip from clogging. In order to control the temperature of the fluids in the chip, two zones were defined of which the temperatures could be individually controlled via home-built Peltier elements (CP 0.8-7-06L, Melcor, USA), glued pair wise onto two copper blocks. The temperature of these blocks was measured with miniature Pt-100 temperature sensors. The Peltier elements were mounted on top of the chip and for removal of the excess heat generated by the Peltier elements a heat sink was used. The inlet-side of the chip was controlled at $10^{\circ} \mathrm{C}$ and the temperature of the reaction zone in the range of $20-100{ }^{\circ} \mathrm{C} .{ }^{1} \mathrm{H}$ NMR spectroscopy $(400 \mathrm{MHz})$ using a microprobe (CapNMR; $5 \mu \mathrm{L}$ flow cell, $1.5 \mu \mathrm{L}$ observation volume) was used to analyse the composition of the reaction mixture formed in the chip, using an $8-10 \mu \mathrm{L}$ sample collected at the outlet of the continuous-flow chip. The time required to collect enough sample volume depended on the applied pressure (but was less then $20 \mathrm{~min}$ for pressures above 100 bar). The carbamic acid formation was investigated for working pressures of 10, 150, 200,300, and 400 bar at 60 and $100^{\circ} \mathrm{C}$.

\section{Results and discussion}

\subsection{Bond inspection}

Comparison of the results of wafer-scale inspection revealed a rather striking difference: after the standard procedure (i), some large bubbles and blisters (diameter up to $3 \mathrm{~mm}$ ) were observed as well as voids and small (white) particles. Only a few voids and particles were seen near wafer edges after procedure (ii), giving a nearly $100 \%$ yield in bonded chips.
In Fig. 5, the measured reflection across the interface between the glass wafers is shown for three different cases: a waferstack bonded with standard bonding procedure (i), the upgraded procedure (ii), and a stack exposed to the upgraded procedure excluding the final anneal step at $600^{\circ} \mathrm{C}$.

For waferstacks exposed to bonding procedures (i) and (ii), the reflectivity of the bond interface is smaller than $10^{-6}$, while for the waferstack that is not annealed the reflectivity is $1.4 \times 10^{-4}$. A waferstack bonded with the standard procedure (i) excluding the final annealing step also showed a high reflectivity at the interface (not shown here). Using thin film optics calculations (Eq. (2)), it is found that a reflectivity of $1.4 \times 10^{-4}$ corresponds to a dielectric layer of air with a thickness of $1 \mathrm{~nm}$, or, alternatively, a layer of water with a thickness of about $5 \mathrm{~nm}$. It is assumed that gas or residual water that is trapped in the nanometer sized roughness of the bond interface is not present anymore at this interface after the final annealing step at $600{ }^{\circ} \mathrm{C}$.

Based on the results of Fig. 5 it can be concluded that it is crucial to perform the annealing step at $600^{\circ} \mathrm{C}$. In that case no interface between the wafers can be distinguished, whereas the interface is clearly perceptible when the annealing step is not carried out. The reflectance measurements do not show a difference between the two bonding procedures, no noticeable difference in reflection is found between the stacks (Fig. 5a and b-measurements reproducible at locations without voids/particles). Nevertheless, when the results of visual inspection are combined with the confocal microscopy results, it can be concluded that the upgraded bonding procedure (ii) yields the best glass-glass direct bond.

\subsection{Pressure tests}

Fig. 6 shows the maximum pressure $p_{\max }$ obtained with pressurized $\mathrm{CO}_{2}$ (a) and $\mathrm{H}_{2} \mathrm{O}$ (b) of all inlet/outlet geometries described in Figs. 2 and 3. Data points are averages over at least three experiments.

From the graphs in Fig. 6 several conclusions can be drawn. Overall, geometries with small cross-sections (Fig. 2c-e) are significantly stronger than structures with a larger cross-section (Fig. $2 \mathrm{a}$ and $\mathrm{b}$ ), and show less spreading in $p_{\max }$. The use of a capping in the top wafer to reduce high local stresses slightly increases $p_{\max }$ (Fig. $2 \mathrm{~b}$ versus a), whereas reduction of the cross-sectional area results in a significant increase in $p_{\max }$ (Fig. $2 \mathrm{c}, \mathrm{d}$ versus b). Moreover, in case of small inlets that are fabricated with powderblasting and HF-etching (Fig. 2c and d), there is a trend that a more gradual transition from the inlet to the microchannel (Fig. 3, sharp tip) results in a higher $p_{\max }$-value. For configurations with these small cross-sections Loctite resin resulted in somewhat higher maximum pressures than Araldite Rapid. Since Loctite is slightly less viscous than Araldite Rapid, this glue fills a larger area between the fiber and the inlet/outlet structure, giving a lower 'dead volume' around the fiber (Fig. 1b) and a higher $p_{\max }$. The highest maximum pressures were obtained with geometry (Fig. 2e), i.e. tubular structures made with HF-etching only. 

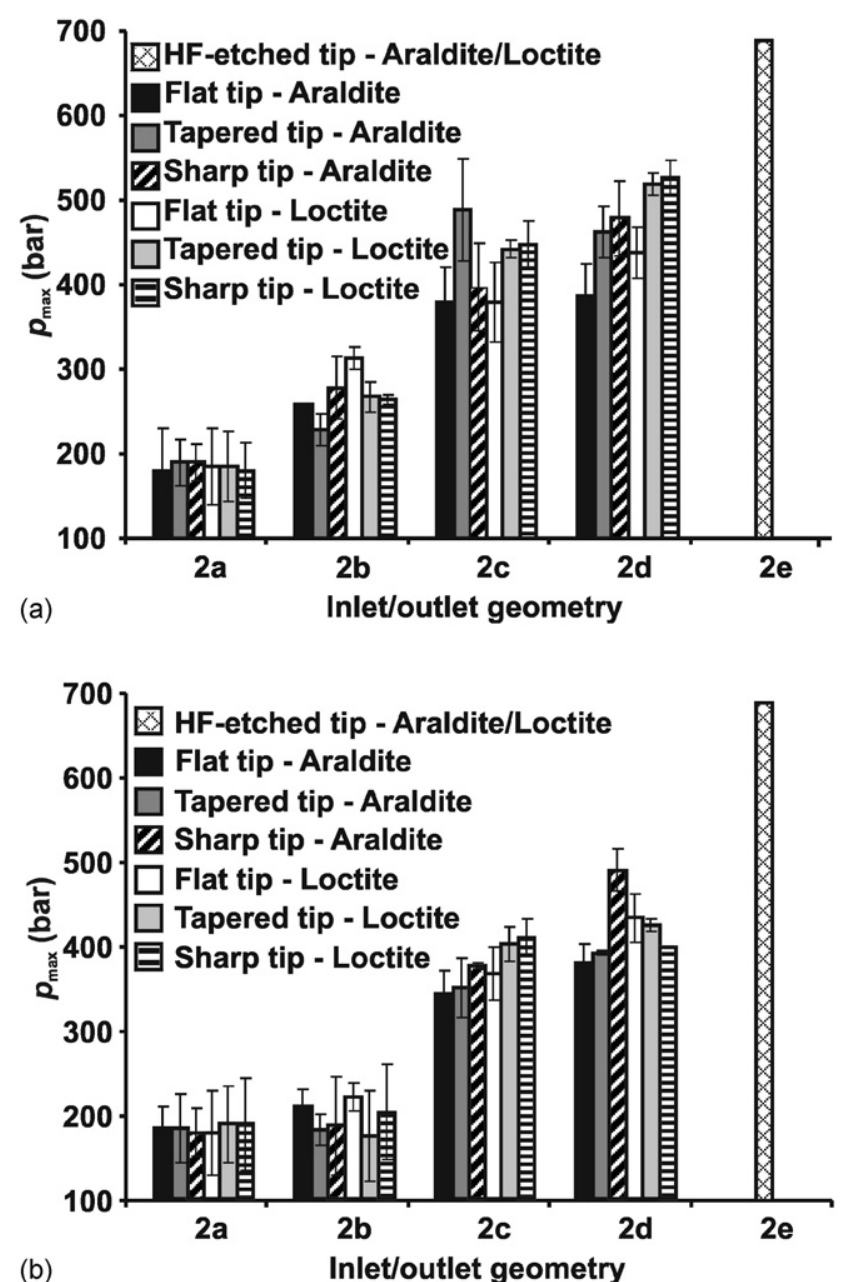

Fig. 6. Maximum pressures ( $\left.p_{\max }\right)$ obtained with dedicated test-chips containing in-plane geometries as described in Figs. 2 and 3 using $\mathrm{CO}_{2}(1)$ as medium (a) or $\mathrm{H}_{2} \mathrm{O}(\mathrm{b})$.

Independent of the glue type, chips with geometry (Fig. 2e) did not fail up to the maximum pressure of the HPLC pump, 690 bar.

A remarkable difference in the type of failure was found between the direct-bonded glass-glass chips and the anodic bonded glass-silicon chips. For the majority of the direct bonds ( $\sim 95 \%$ ), failure occurred due to release of the bond, as could clearly be seen from the position where liquid droplets formed when the chips failed. However, for the anodic bonded chips failure was always due to out-of-plane cracking of the glass part of the chips, showing that not the bond was the limiting factor, but the mechanical strength of the glass.

The obtained $p_{\max }$-values were $30-70$ bar lower in case of $\mathrm{H}_{2} \mathrm{O}$ compared to $\mathrm{CO}_{2}(1)$. This is a well-known effect, since due to the passivation of a freshly created glass surface with silanol groups a crack in the glass (or a rupturing interface) will be stabilized in $\mathrm{H}_{2} \mathrm{O}$, a process that will not occur in $\mathrm{CO}_{2}$ [36].

From the pressure experiments it can be seen that the optimal inlet-geometry for microreactor chips for high-pressure chemistry is the tubular structure etched with HF. Beside that

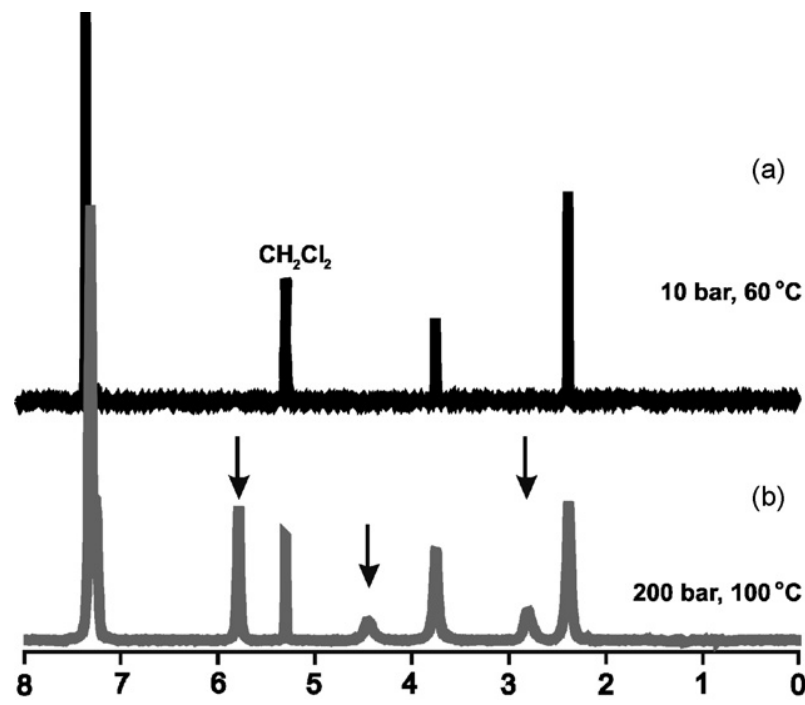

Fig. 7. ${ }^{1} \mathrm{H}$ NMR spectra of $N$-benzylmethylamine $(\alpha)$ (a) and mixture of $(\alpha)$ and benzylmethyl-carbamic acid $(\gamma)$ (indicated by arrows) (b).

this geometry (Fig. 2e) has the optimal cross-section to obtain high pressures [26], this structure also does not suffer from microcracks that are due to powderblasting [25]. On the other hand, small powderblasted inlets/outlets with a sharp transition towards the flow channels (geometry, Fig. 2c) are adequate for working pressures up to $300 \mathrm{bar}$.

\subsection{Reaction in high-pressure glass microreactor chip}

Microreactors equipped with tubular inlets and outlets suitable for $110 \mu \mathrm{m}$ outer diameter fibers (geometry, Fig. 2e) were used for studying the formation of the carbamic acid by reaction of $N$-benzylmethylamine and $\mathrm{CO}_{2}$. The ${ }^{1} \mathrm{H}$ NMRspectra (Fig. 7) clearly show that the product is formed at $200 \mathrm{bar}\left(100^{\circ} \mathrm{C}\right.$, residence time in chip $\left(t_{\mathrm{R}}\right)$ approximately $\left.8.3 \mathrm{~s}\right)$, whereas at $10 \mathrm{bar}\left(60^{\circ} \mathrm{C}, t_{\mathrm{R}} \sim 166 \mathrm{~s}\right)$ no product formation was observed.

The carbamic acid formation was confirmed by mass spectrometry (ESI-TOF) in negative mode. At a working pressure of $300 \mathrm{bar}\left(100^{\circ} \mathrm{C}, t_{\mathrm{R}} \sim 5.5 \mathrm{~s}\right)$ the product was still observed, although the conversion was lower than for 200 bar. At 400 bar (and $100{ }^{\circ} \mathrm{C}, t_{\mathrm{R}} \sim 4.1 \mathrm{~s}$ ), however, no product was detected. Apparently, in the latter case the residence time in the chip was too small to perform the reaction. This is due to the fact that the residence time depends on the applied pressure. A redesign of the high-pressure microreactor, i.e. a chip with an improved fluidic resistor (4 in Fig. 1a), is needed to obtain longer residence times. Nevertheless, the high-pressure microreactor chips could be operated at 400 bar without problems.

\section{Conclusions}

In this contribution the design, fabrication and high-pressure performance of several in-plane fiber-based interface geometries to microreactor chips for high-pressure chemistry are discussed. 
The main investigated design parameters are the geometry of the inlet/outlet structure (i.e. cross-sectional shape and size), the manner in which top and bottom wafer are connected and the way in which the inlets/outlets turn over into the microfluidic channels of the chip.

From visual inspection (wafer-scale) and confocal microscopy, it is found that a bonding procedure including an additional cleaning step with $\mathrm{HNO}_{3}$ and a step during which the waferstack is compressed with a high force $(\sim 11$ metric tons) yields the best glass-glass direct bond.

Pressure experiments revealed that the optimal inletgeometry for microreactor chips for high-pressure chemistry is a tubular structure that is etched with $\mathrm{HF}$ and suitable for fibers with an outer diameter of $110 \mu \mathrm{m}$. These inlet/outlet geometries can withstand pressures up to $690 \mathrm{bar}$. Small powderblasted inlets/outlets that are smoothened with HF and with a sharp transition towards the flow channels are adequate for working pressures up to 300 bar.

Microreactors equipped with these tubular inlets/outlets were used to study the formation of the carbamic acid of $\mathrm{N}$-benzylmethylamine and $\mathrm{CO}_{2}$. For working pressures up to 300 bar the product was clearly detected. For working pressures up to 400 bar the chips functioned well (i.e. no failure), although no product was observed due to too small residence times of the reactants in the chip. The experiments show that these micromachined microreactor chips are attractive tools for performing high-pressure chemistry in a fast and safe way.

\section{Acknowledgements}

This research is supported by the Dutch Technology Foundation STW, applied science division of NWO, and by NanoNed, a national nanotechnology program coordinated by the Dutch Ministry of Economic Affairs. Part of this work was also financially supported by the German Science Foundation (DFG), priority program SP1164 (micro- and nanofluidics).

\section{References}

[1] G. Jenner, High pressure and selectivity in organic reactions, Tetrahedron 53 (8) (1997) 2669-2695.

[2] F.G. Klärner, F. Wurche, The effect of pressure on organic reactions, J. Prakt. Chem. 342 (7) (2000) 609-636.

[3] M. Kotowski, R. van Eldik, Application of high-pressure kinetic techniques to mechanistic studies in coordination chemistry, Coord. Chem. Rev. 93 (1) (1989) 19-57.

[4] F. Amita, H. Oka, M. Mukaide, Y. Irasaki, K. Takegoshi, T. Terao, O. Kajimoto, Development of a high-temperature and high-pressure nuclear magnetic resonance probe for studies of chemical reactions in supercritical water, Rev. Sci. Instrum. 75 (2) (2004) 467-471.

[5] V. Hessel, S. Hardt, H. Löwe, Chemical Microprocess Engineering, Wiley-VCH, Weinheim, Germany, 2004.

[6] K.F. Jensen, Microreaction engineering -is small better? Chem. Eng. Sci. 56 (2) (2001) 293-303.

[7] D.C. Hendershot, Process minimization: making plants safer, Chem. Eng. Progr. 96 (1) (2000) 35-40.

[8] K.F. Jensen, Microchemical sytems: status, challenges and opportunities, AIChE J. 45 (10) (1999) 2051-2054.
[9] F. Benito-Lopez, W. Verboom, M. Kakuta, J.G.E. Gardeniers, R.J.M. Egberink, R.E. Oosterbroek, A. van den Berg, D.N. Reinhoudt, Optical fiber-based on-line UV/vis spectroscopic monitoring of chemical reaction kinetics under high pressure in a capillary microreactor, Chem. Commun. 22 (2005) 2857-2859.

[10] W. Ehrfeld, V. Hessel, H. Löwe, Microreactors: New Technology for Modern Chemistry, VCH, Weinheim, Germany, 2000.

[11] A.J. Franz, K.F. Jensen, M.A. Schmidt, Palladium membrane microreactors, in: Tech. Digest Third International Conference on Microreaction Technology (IMRET 3), Frankfurt am Main, Germany, April 18-21, 1999, pp. $267-276$.

[12] S. Chattopadhyay, G. Veser, Heterogeneous-homogeneous interactions in catalytic microchannel reactors, AIChE J. 52 (6) (2006) 22172229.

[13] N. Stoll, I. Hawali, K. Thurow, Automated microdosing system for integration with a miniaturized high-pressure reactor system, J. Autom. Methods Man. Chem. 4 (2005) 230-234.

[14] J. Kobayashi, Y. Mori, S. Kobayashi, Hydrogenation reactions using $\mathrm{scCO}_{2}$ as a solvent in microchannel reactors, Chem. Commun. 20 (2005) 2567-2568.

[15] S.M. Stishov, A.E. Petrova, A method for the hermetic connection of highpressure tubing to a high-pressure apparatus, Instrum. Exp. Techn. 46 (5) (2003) 719-720.

[16] Y. Shintani, K. Hirako, M. Motokawa, Y. Takano, M. Furuno, H. Minakuchi, M. Ueda, Polydimethylsiloxane connection for quartz microchips in a highpressure system, Anal. Sci. 20 (12) (2004) 1721-1723.

[17] L. Szekely, R. Freitag, Fabrication of a versatile microanalytical system without need for clean room conditions, Anal. Chim. Acta 512 (1) (2004) $39-47$.

[18] B.L. Gray, D. Jaeggo, N.J. Mourlas, B.P. van Drieënhuizen, K.R. Williams, N.I. Maluf, G.T.A. Kovacs, Novel interconnection technologies for integrated microfluidic systems, Sens. Actuators A 77 (1) (1999) 57-65.

[19] H. Andersson, W. van der Wijngaart, P. Enoksson, G. Stemme, Micromachined flow-through filter-chamber for chemical reactions on beads, Sens. Actuators B 67 (1-2) (2000) 203-208.

[20] C.-H. Chiou, G.-B. Lee, H.-T. Hsu, P.-W. Chen, P.-C. Liao, Micro devices integrated with microchannels and electrospray nozzles using PDMS casting techniques, Sens. Actuators B 86 (1) (2000) 280-286.

[21] A.V. Pattekar, M.V. Kothare, Novel microfluidic interconnectors for high temperature and pressure applications, J. Micromech. Microeng. 13 (2) (2003) 337-345.

[22] V. Nittis, R. Fortt, C.H. Legge, A.J. de Mello, A high-pressure interconnect for chemical microsystem applications, Lab. Chip 1 (2) (2001) 148-152.

[23] M. Brivio, R.E. Oosterbroek, W. Verboom, A. van den Berg, D.N. Reinhoudt, Simple chip-based interfaces for on-line monitoring of supramolecular interactions by nano-ESI MS, Lab. Chip 5 (10) (2005) $1111-1122$.

[24] Upchurch Scientific Inc., Oak Harbor, WA, USA (www.upchurch.com).

[25] R.E. Oosterbroek, D.C. Hermes, M. Kakuta, F. Benito-Lopez, J.G.E. Gardeniers, W. Verboom, D.N. Reinhoudt, A. van den Berg, Fabrication and mechanical testing of glass chips for high-pressure synthetic or analytical chemistry, Microsyst. Technol. 12 (5) (2006) 450-454.

[26] R.H. Doremus, Glass Science, Wiley, New York, USA, 1973.

[27] A. Plöß1, G. Kräuter, Wafer direct bonding: tailoring adhesion between brittle materials, Mater. Sci. Eng. R25 (1-2) (1999) 1-88.

[28] D.C. Hermes, T. Heuser, E.J. van der Wouden, J.G.E. Gardeniers, A. van den Berg, Fabrication of microfluidic networks with integrated electrodes, Microsyst. Technol. 12 (5) (2006) 436-440.

[29] T. Wilson, Confocal Microscopy, Academic Press, 1990, pp. 1-64.

[30] M. Born, E. Wolf, Principles of Optics, 7th ed., Cambridge University Press, UK, 1973.

[31] H. Rathgen, F. Mugele, Confocal reflectometry: a new tool for studying burried interfaces, in press.

[32] M. Aresta, Carbon dioxide: an effective source of carbon for the chemical industry, Abstr. Papers Am. Chem. Soc. 223 (2002) 576.

[33] M. Aresta, A. Dibenedetto, Mixed anhydrides: key intermediates in carbamates forming processes of industrial interest, Chem. Eur. J. 8 (3) (2002) 685-690. 
[34] J.J. Shulik, G. Sartori, W.S. Ho, W.A. Thaler, G.E. Milliman, J.C. Wilbur, A novel $\mathrm{V}^{5+}$ stable $\mathrm{K}_{2} \mathrm{CO}_{3}$ promoter for $\mathrm{CO}_{2}$ absorption, Sep. Sci. Technol. 31 (12) (1996) 1663-1673.

[35] H. Fischer, O. Gyllenhaal, J. Vessman, K. Albert, Reaction monitoring of aliphatic amines in supercritical carbon dioxide by proton nuclear magnetic resonance spectroscopy and implications for supercritical fluid chromatography, Anal. Chem. 75 (3) (2003) 622-626.

[36] S.M. Wiederhorn, S.W. Freiman, E.R. Fuller Jr., C.J. Simmons, Effects of water and other dielectrics on crack growth, J. Mater. Sci. 17 (12) (1982) $3460-3478$ 